\title{
Physicians' and Nurses' Perspectives on Increased Family Reports of Pain in Dying Hospitalized Patients
}

\author{
SUSAN E. HICKMAN, Ph.D.,1,2 SUSAN W. TOLLE, M.D., F.A.C.P., ${ }^{1,3}$ and \\ VIRGINIA P. TILDEN, D.N.Sc., R.N., F.A.A.N. ${ }^{2,1}$
}

\begin{abstract}
Many indicators suggest that care of the dying in Oregon has been improving over the past decade. However, results from a recent study suggest that one aspect of care of the dying, pain management, may be worsening. In late 1997, family reports of moderate and severe pain in dying hospitalized patients increased from $33 \%$ to $57 \%$. This occurred during a volatile time in the Oregon political climate associated with events surrounding a second vote on physician-assisted suicide. In order to better understand the observed increase better, a statewide sample of physicians and nurses was surveyed to obtain their opinions about factors that may have contributed to the increased family reports of moderate and severe pain in dying hospitalized patients. Seventy-nine percent of respondents endorsed two or more factors as partial explanations. These factors include an increase in family expectations about pain management (endorsed by $96 \%$ ), decreased physician prescribing (endorsed by $66 \%$ ), and reduced nurse administration of pain medication (endorsed by 59\%). Physicians who thought reduced physician prescribing was a partial factor rated fears of the Board of Medical Examiners and the Drug Enforcement Administration as the most likely explanations for decreased prescribing. More research is needed to better understand family expectations for end-of-life care, fears of investigation, and pain medication practices.
\end{abstract}

\section{INTRODUCTION}

$\mathbf{N}$ UMEROUS INDICATORS SUGGEST that care of the dying in Oregon has been improving over the past decade. ${ }^{1}$ Research suggests that Oregon has high rates of advance planning ${ }^{2,3}$ and the lowest in-hospital death rate in the country. 4,5 Oregon also has one of the highest rates of hospice utilization in the country. ${ }^{6}$

It appeared that Oregon was also making headway in the area of pain management for the dying, with rates of morphine prescriptions among the highest per capita in the country ${ }^{7}$ and an increase in palliative care teams in acute care hospitals across the state. ${ }^{8}$ However, a recent study yielded data suggesting that for the first time in 10 years, an aspect of care of the dying in Oregon was worsening. In a 14-month study of family members of 475 Oregon decedents whose deaths occurred during 1996-1997, an average of $34 \%$ of families reported that their loved one had moderate or severe pain in the last week of life. ${ }^{2}$ Analysis of the data by time period and by location of death revealed a concerning finding: Fam-

\footnotetext{
${ }^{1,3}$ Center for Ethics in Health Care, Oregon Health Sciences University, Portland, Oregon

${ }^{2}$ School of Nursing, Oregon Health Sciences University, Portland, Oregon.

${ }^{3}$ School of Medicine, Oregon Health Sciences University, Portland, Oregon.
} 
ily reports of moderate and severe pain increased from $33 \%$ to $57 \%$ for dying hospitalized patients during the last 3 months of 1997.

It was unclear whether this increase in family reports of pain was a temporary increase due to a volatile political and regulatory climate in Oregon or the harbinger of something more permanent and troubling. The increase in family reports of pain occurred in close proximity to the legalization of physician-assisted suicide, a second public vote on whether physician-assisted suicide should continue to be legal, related intense media coverage, and a letter from the Drug Enforcement Administration (DEA) raising questions about the legality of using controlled substances for physician-assisted suicide. The timing of the finding raised two pressing questions: Did the increase in family reports of moderate and severe pain continue in 1998? And what factors may have contributed to the observed increase?

In order to attempt to answer these questions, two follow-up studies were conducted. First, additional data were collected about in-hospital deaths that occurred in late $1998 .^{8}$ The methodology from the first study ${ }^{2}$ was replicated for inhospital deaths that occurred in October, November, and December 1998. In this follow-up study, family members reported in late 1998 that $54 \%$ of their dying loved ones had moderate or severe pain, a figure comparable to the $57 \%$ reported in late 1997. This finding suggested that the original finding was not an aberration and that increased reports of pain for dying hospitalized patients continued in 1998.

Unfortunately, neither the original study nor the follow-up study were designed to provide an explanation about why the reported increase occurred. Therefore, a mailed opinion survey was conducted with practicing Oregon physicians and nurses to assess their perspective on the reasons behind the increased family reports of moderate and severe pain in dying hospitalized patients.

\section{METHODS}

\section{Participants}

The sample was derived from mailing lists maintained by the Oregon Board of Medical Examiners (BME) and the Oregon State Board of Nursing (SBN). The sample consisted of physi- cians and nurses in all 36 Oregon counties with active licenses who were likely to care for dying patients in a hospital setting. Physician specialities included family practice, general practice, and internal medicine. Nursing specialities included clinical nurse specialists, nurse managers, and staff nurses employed in hospitals in the following areas: critical care, geriatrics, general nursing, med-surgery, and oncology. A stratified systematic random sampling procedure was used to provide broad geographic representation and avoid oversampling of the Portland metropolitan area, which contains half of the state population. Ten physicians and 10 nurses per county were selected from most Oregon counties. Thirty physicians and 30 nurses were selected from each of the three counties that make up the Portland metropolitan area. In sparsely populated counties with fewer than 10 eligible physicians or nurses, all eligible physicians and nurses were sampled. Survey packets were mailed to 743 potential respondents. When possible, participants whose survey packets were returned as undeliverable, who had moved out of the county, or who declared themselves ineligible were replaced with another physician or nurse from the same county, selected using a systematic random sampling procedure. The final sample consisted of 723 potential respondents.

\section{Procedure}

The opinion survey assessed physicians' and nurses' opinions about factors that may have contributed to the increase in family reports of moderate and severe pain in dying hospitalized patients in late 1997. The survey was conducted between October 1998 and December 1998. Human subjects approval was granted by the Oregon Health Sciences University Institutional Review Board prior to the start of the study. Each potential respondent received a packet containing a survey, a letter of introduction reporting the finding of increased pain in hospitalized dying patients in late 1997, and a postage-paid return envelope. Each survey was marked with a code so that the respondent's discipline and county could be tracked. The code also permitted identification of nonresponders so that they could be recontacted to increase participation rates. The code key was kept separately from individual survey responses and destroyed after data collection was complete. Individuals who did not respond were sent a re- 
minder postcard 2 weeks after the initial mailing. Nonresponders were sent a second copy of the survey approximately 2 weeks after the reminder postcard. A total of 411 out of 723 participants (189 physicians and 222 nurses) returned completed confidential surveys, a response rate of $57 \%$.

\section{Study data}

The survey was pilot tested with 20 primary care physicians and hospital-based nurses at Oregon Health Sciences University. Participants were asked to complete the survey and provide feedback about the survey design. These suggestions were incorporated into the final version of the survey.

The opinion survey consisted of questions about why family reports of patient pain increased for in-hospital deaths in late 1997. Four possible reasons were identified about why this increase in family reports of moderate or severe pain might have occurred: (1) pain did not increase but families were more aware of pain management issues; (2) pain did increase because physicians ordered less pain medication; (3) pain did increase because nurses administered less pain medication; and (4) pain did increase because pharmacists dispensed less pain medication (Table 1). Each item was followed by a 7point Likert scale, ranging from 0 (not a factor) to 6 (full explanation) with 3 labeled as a "partial factor." Ratings of 0 and 1 were considered to be indicative that participants did not think the item was a factor in increased reports. Respondents who thought that either reduced physician ordering or reduced nurse administration of pain medications played a role were asked to rate the extent to which various fears played a role in this behavior. Space was provided to write in other explanations or comments.

\section{RESULTS}

Overall, $79 \%$ of participants endorsed two or more factors as partial explanations for the observed increase in family reports of pain for dying hospitalized patients. Table 1 shows physicians' and nurses' opinions about factors they thought contributed to the increase. Ninety-six percent of physicians and nurses thought that increased family awareness of pain management was a contributing factor. Both physicians and nurses rated increased family awareness of pain management issues higher $(x=3.8)$ than the other factors presented in the survey (paired $t$ tests of all possible comparisons indicated that respondents ranked family awareness significantly higher than the other factors at $p \leq .001$ for all comparisons).

Sixty-six percent of all respondents thought decreased physician prescribing was a factor in in-

Table 1. Physicians' and Nurses' Views of Factors that Contributed to Increased Reports of Pain in Dying Hospitalized Patients in Late 1997

\begin{tabular}{|c|c|c|c|}
\hline Item & $\begin{array}{c}\text { Physicians } \\
\text { Mean (SD) } \\
\mathrm{n}=189\end{array}$ & $\begin{array}{c}\text { Nurses } \\
\text { Mean (SD) } \\
\mathrm{n}=222\end{array}$ & $\stackrel{\mathrm{n}}{\text { physicians/nurses }}$ \\
\hline Families were more aware of pain management issues & $3.8(1.2)$ & $3.8(1.2)$ & $186 / 218$ \\
\hline Physicians ordered less pain medication & $2.2(1.5)$ & $2.7(1.7)$ & $185 / 218$ \\
\hline . . because of fears of the Board of Medical Examiners ${ }^{a}$ & $3.7(1.6)$ & $2.6(1.5)$ & $107 / 145$ \\
\hline . . because of fears of the Drug Enforcement Agency ${ }^{a}$ & $3.4(1.6)$ & $2.5(1.5)$ & $107 / 146$ \\
\hline $\begin{array}{l}\text {. . because of fears of being accused by colleagues of } \\
\text { participating in assisted suicide }{ }^{a}\end{array}$ & $2.4(1.5)$ & $2.5(1.5)$ & $107 / 146$ \\
\hline ... because of fears of media scrutiny ${ }^{a}$ & $2.4(1.7)$ & $2.5(1.5)$ & $107 / 146$ \\
\hline Nurses administered less pain medication & $2.0(1.5)$ & $2.1(1.5)$ & $183 / 216$ \\
\hline . . because of fears of the State Board of Nursing ${ }^{a}$ & $2.9(1.4)$ & $2.2(1.6)$ & $97 / 125$ \\
\hline .. because of fears of employer censure ${ }^{a}$ & $2.4(1.5)$ & $2.3(1.6)$ & $99 / 125$ \\
\hline $\begin{array}{l}\text {. because of fears of being accused by colleagues of } \\
\text { participating in assisted suicide }{ }^{\mathrm{a}}\end{array}$ & $2.3(1.5)$ & $2.1(1.5)$ & $99 / 127$ \\
\hline ... because of fears of media scrutiny ${ }^{a}$ & $2.2(1.5)$ & $1.9(1.5)$ & $98 / 125$ \\
\hline Pharmacists dispensed less pain medication & $1.3(1.3)$ & $1.2(1.3)$ & $185 / 218$ \\
\hline
\end{tabular}

Note: Scale ranged from 0 (not a factor) to 6 (full explanation). Possible factors are left-justified and in bold. Related fears are indented. Not all sample sizes are the same because some participants did not respond to every item.

${ }^{a}$ Of those who thought decreased prescribing or administration occurred. 
creased family reports of pain for dying hospitalized patients. Physicians endorsed this factor at a moderate level $(x=2.2)$, as did nurses ( $x=$ 2.7). Physicians who thought decreased physician prescribing was a factor in increased family reports of pain in dying hospitalized patients rated two factors highest: fears of the BME $(x=3.7)$ and fears of the DEA $(x=3.4)$. Paired $t$ tests revealed that both were rated similarly to each other but significantly higher than ratings of fears of accusations of assisted suicide ( $x=2.4: p \leq .001)$, and fears of media scrutiny ( $x=2.4: p \leq .001)$.

Fifty-nine percent of all respondents thought that reduced nurse administration of pain medication was a factor. Nurses rated this at a moderate level $(x=2.1)$, as did physicians $(x=2.0)$. Nurses who thought reduced nurse administration helped explain increased family reports of moderate and severe pain in dying hospitalized patients rated fears of employer censure $(x=2.3)$, fears of the State Board of Nursing $(x=2.2)$, and fears of accusations of participating in assisted suicide $(x=2.1)$ similarly (paired $t$ test comparisons were not significantly different). Only $33 \%$ of respondents thought that reduced dispensing by pharmacists helped explain the observed increase. Physicians and nurses rated this at a low level $(x=1.3)$.

When asked in an open-ended item whether they could suggest any other explanations for the increased reports of pain at the end of 1997, many respondents reemphasized the factors in the survey, including increased family expectations and physician fears of regulatory boards. Other suggested explanations included increased patient awareness of pain management leading to increased reports of pain to family members, staffing shortages, physicians' and nurses' concerns about being accused of euthanasia by family members, and the development of the unrealistic expectation that all pain can be managed.

\section{DISCUSSION}

Physicians and nurses view the increase in family reports of moderate and severe pain for dying hospitalized patients in late 1997 as multicausal, with $79 \%$ or respondents endorsing two or more factors as partial explanations. The most frequently cited explanations were that family members had higher expectations about pain management, that physicians prescribed less medication due to fears of scrutiny by regulatory agencies, and that nurses administered less pain medication due to multiple fears.

There has been little research on family expectations for pain management and how these effect perceptions of pain control. If family expectations did indeed increase due to factors such as the media coverage about palliative care in late 1997, this may have led to less tolerance for untreated or undertreated pain in dying patients. However, this raises the question of why a similar increase in family expectations was not seen in family members of patients dying at home or in nursing homes. One possible explanation is that some Oregon hospitals have undertaken aggressive campaigns to increase attention to pain. For example, some hospitals in Oregon have made pain the fifth vital sign while others have posted signs with pain scales in patient rooms, requesting that patients report the pain they experience to staff. Numerous hospitals have developed palliative care or comfort care teams, calling special attention to pain and symptom management. ${ }^{8}$ Further research is needed into how perceptions and expectations affect reports of pain in dying patients.

Most physicians and nurses also indicated that reduced physician prescribing played a role in increased family reports of moderate and severe pain for dying hospitalized patients. The two factors endorsed most highly as a reason for reduced physician prescribing were fears of the Oregon BME and fears of the DEA. There is a growing body of literature about the negative impact of fears of regulatory boards on physician prescribing of controlled substances. ${ }^{10-13}$ Experts concur that fears of investigation, regardless of how realistic, do alter physician prescribing practices. ${ }^{12,14}$ One possible reason is that regulatory guidelines are vague and depend on the interpretation of medical boards. ${ }^{15}$ In the 1980 s, the Oregon BME was known for its aggressiveness in investigating physicians for overprescribing narcotics. ${ }^{16}$ Some physicians remain fearful of BME investigations and these fears may have been reactivated or reinforced after the Board's disciplinary action against a physician for euthanasia of a patient who died in a hospital emergency room in the summer of $1997 .{ }^{17}$

Survey respondents ranked fears of the BME and fear of the DEA as almost equivalent contributors to reduced physician prescribing of pain medications. After the 1997 vote on physician-as- 
sisted suicide, the Department of Justice issued a letter warning physicians that their prescribing licenses were at risk and that they could face severe sanctions if they helped someone commit suicide using controlled substances. ${ }^{18}$ It is possible that the Justice Department's letter of warning had an adverse effect on physicians prescribing pain medications in the care of their dying hospitalized patients. Physicians in the hospital setting are subject to greater scrutiny by a larger number of people than physicians in the community, increasing the possibility that someone will disagree with medications given to dying patients and involve the authorities. In a review of cases of criminal prosecutions of physicians related to care of the dying, all but 1 of 11 cases was for care in the hospital and all but 1 of the cases was brought to the prosecutor's attention by hospital staff. ${ }^{19}$ While these cases represent a small number of physicians, they are typically widely publicized and provide a backdrop for increased fears in the hospital setting, especially at a time when increased scrutiny has been threatened. Further research is needed to better understand the connection between fears of investigation and physician prescribing practices.

Survey respondents also indicated that they thought reduced nurse administration of pain medication may have played a role in increased family reports of pain in dying hospitalized patients. At times, nurses have some flexibility with "as-needed" orders in determining frequency and dosage within a prescribed range. Nurses do provide the majority of direct patient care in the hospital and are responsible for ongoing assessment of the patient's condition, requesting and administering additional pain medications when needed. It is possible that some nurses were frightened by a climate of scrutiny and altered their practice in late 1997 by reducing the dosage or interval of pain medication administration or less vigorously requesting increased dosage orders.

Interestingly, pharmacists were not thought to have significantly contributed to increased family reports of moderate and severe pain in dying hospitalized patients. This may be in part because pharmacists are already subject to intense regulatory scrutiny, ${ }^{10}$ making the threat of increased scrutiny less relevant. The perceptions may also be due to the less direct role played by pharmacists in determining medication dosing.
The increase in family reports of pain occurred at a time when Oregon morphine prescriptions were rising, raising questions about the validity of the family reports that pain increased. Oregon is a leader in morphine usage per capita and has been for several years. ${ }^{7}$ While the data suggest that Oregon patients are generally receiving more pain medication than patients in many other states, this does not contradict increased reports of pain in dying hospitalized patients. It is possible that total morphine use was on the rise in Oregon for the majority of patients in pain (e.g., those with chronic severe pain and acute pain after surgery), while prescriptions dropped for the smaller numbers of patients dying in hospitals. Unfortunately, no data are available to determine which specific patient populations are receiving an increase in morphine prescriptions and the actively dying are unidentifiable in current federal data collection methods.

A major limitation of this study is that it is an opinion survey about family reports of pain. Reports of pain were not verified by patient records or direct observations. Although physicians and nurses seem like a logical group to provide us with an explanation about why this observed increase occurred, it is possible that physicians and nurses are not the best source of information about the observed trend. ${ }^{20,21}$ We intend to undertake investigation of further sources of information. Furthermore, the random sample in this study may not have been the ideal sample of physicians and nurses with whom to explore this issue. Nonresponders may have differed from responders in some important way. The reason behind the increased family reports of pain is undoubtedly very complex. It is likely that the study did not identify all contributing causes, though the vast majority of respondents were unable to generate additional hypotheses when asked.

It is unlikely that the families in our earlier studies were completely wrong in their reports of more pain in their dying loved ones. Whether families are reporting pain more frequently primarily because of altered expectations or whether patients are experiencing more pain because of decreased medication, the increased reports of moderate and severe pain for dying hospitalized patients deserve further attention. It is clear that too many Oregonians are dying in pain. More research is needed to better understand the relationships between family and patient perceptions of care at the end of life, threats of investigation, 
and both physician and nurse pain medication practices.

\section{ACKNOWLEDGMENTS}

Partial support for this project comes from The Robert Wood Johnson Foundation and The Nathan Cummings Foundation. The views expressed are those of the authors and do not necessarily represent those of the funding agencies.

We thank Senior Research Assistant Christie Bernklau Halvor, MSSW, for her help with data collection and data management.

\section{REFERENCES}

1. Lee MA, Tolle SW: Oregon's assisted suicide vote: The silver lining. Ann Intern Med 1996;124:267-269.

2. Tolle SW, Tilden VP, Rosenfeld A, Hickman SE: Family reports of barriers to optimal care of the dying. Nurs Res 2000;49:310-317.

3. Teno JM, Branco KJ, Mor V, Phillips CD, Hawes C, Morris J, Fries BE: Changes in advance care planning in nursing homes before and after the Patient Self-Determination Act: Report of a 10-state survey. J Am Geriatr Soc 1997;45:939-944.

4. Tolle SW, Rosenfeld AG, Tilden VP, Park Y: Oregon's low in-hospital death rates: What determines where people die and satisfaction with decisions on place of death? Ann Intern Med 1999;130:681-685.

5. Wennberg JE, Cooper MM: The Dartmouth Atlas of Health Care 1999. Chicago: American Hospital Publishing, 1999.

6. Cushman JD: Hospice penetration: The use of public data to measure hospice performance. Symposium conducted at the National Hospice Organization Senior Management and Leadership Conference. St. Louis, MO: 1998.

7. Office of Diversion Controls: DADS Quarterly Reports 1999. Arlington, VA: U.S. Department of Justice, 1999.

8. Tolle SW, Tilden VP, Hickman SE, Rosenfeld A, Halvor CB: The Oregon Report Card: Improving Care of the Dying. Portland, OR: Center for Ethics in Health Care, 1999.

9. Tolle SW, Tilden VP, Hickman SE, Rosenfeld AG: Family reports of pain in dying hospitalized patients: a structured telephone survey. West J Med 2000;172: 374-377.

10. Hill CS, Jr: The negative influence of licensing and disciplinary boards and drug enforcement agencies on pain treatment with opioid analgesics. J Pharm Care Pain Symptom Control 1993;1:43-62.

11. Joranson DE, Gilson AM: Regulatory barriers to pain management. Semin Oncol Nurs 1998;14:158-163.

12. Portenoy RK: Chronic opioid therapy in nonmalignant pain. J Pain Symptom Manage 1990;5(Suppl): S46-62.

13. Joranson DE. Federal and state regulation of opioids. J Pain Symptom Manage 1990;5(Suppl):S12-23.

14. Federation of State Medical Boards of the United States: Model Guidelines for the Use of Controlled Substances for the Treatment of Pain. Euless, TX: Federation of State Medical Boards of the United States, Inc., 1998.

15. Hill CS Jr: Government regulatory influences on opioid prescribing and their impact on the treatment of pain of nonmalignant origin. J Pain Symptom Manage 1996;11:287-298.

16. Kofoed L, Bloom JD, Williams MH, Rhyne C, Resnick $\mathrm{M}$ : Physicians investigated for inappropriate prescribing by the Oregon Board of Medical Examiners. West J Med 1989;150:597-601.

17. Hoover E: Physician disciplined for active euthanasia. The Oregonian July 18, 1997; Sect. A:1, 22.

18. Egan T: Threat from Washington has chilling effect on Oregon law allowing assisted suicide. New York Times November 19, 1997; Sect. National:18.

19. Alpers A: Criminal act or palliative care? Prosecutions involving the care of the dying. J Law Med Ethics 1998;26:308-331.

20. Tait RC, Chibnall JT: Physician judgments of chronic pain patients. Soc Sci Med 1997;45:1199-1205.

21. Camp LD: A comparison of nurses' recorded assessments of pain with perceptions of pain as described by cancer patients. Cancer Nurs 1988;11:237-243.

22. Nekolaichuk CL, Bruera E, Spachynski $K$, MacEachern T, Hanson J, Maguire TO: A comparison of patient and proxy symptom assessments in advanced cancer patients. Palliat Med 1999;13:311-323.

Address reprint requests to: Susan E. Hickman, Ph.D. OHSU Center for Ethics in Health Care 3181 SW Sam Jackson Park Road, SNORD Portland, OR 97201

E-mail: hickmans@ohsu.edu 